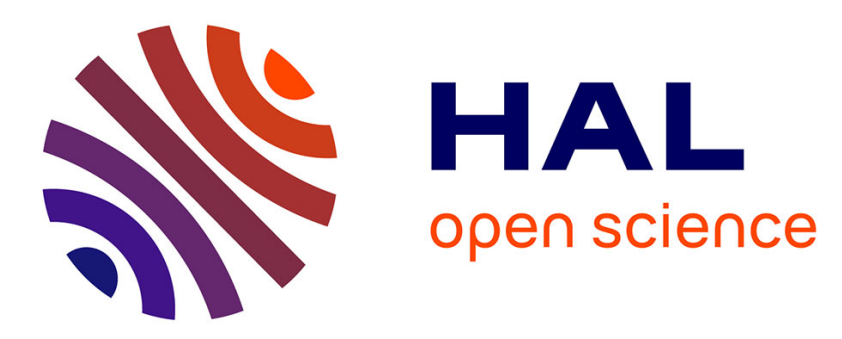

\title{
A methodology to improve the assessment of vulnerability on the maritime supply chain of energy
}

\author{
Martin Tanguy, Aldo Napoli
}

\section{To cite this version:}

Martin Tanguy, Aldo Napoli. A methodology to improve the assessment of vulnerability on the maritime supply chain of energy. Oceans'2015, sponsored by the Marine Technology Society and the IEEE Oceanic Engineering Society, Oct 2015, Washington, DC, United States. hal-01203635

\section{HAL Id: hal-01203635}

https://hal-mines-paristech.archives-ouvertes.fr/hal-01203635

Submitted on 23 Sep 2015

HAL is a multi-disciplinary open access archive for the deposit and dissemination of scientific research documents, whether they are published or not. The documents may come from teaching and research institutions in France or abroad, or from public or private research centers.
L'archive ouverte pluridisciplinaire HAL, est destinée au dépôt et à la diffusion de documents scientifiques de niveau recherche, publiés ou non, émanant des établissements d'enseignement et de recherche français ou étrangers, des laboratoires publics ou privés. 


\title{
A methodology to improve the assessment of vulnerability on the maritime supply chain of energy
}

\author{
Martin TANGUY, Aldo NAPOLI \\ MINES ParisTech, PSL Research University \\ Centre for research on Risk and Crises (CRC) \\ Sophia-Antipolis, France \\ \{martin.tanguy,aldo.napoli\}@mines-paristech.fr
}

\begin{abstract}
-the globalization of trade is due to the transportation possibilities and the standardization (containerization of freight). The dependency of the economy to the sea and to the merchant navy has increase this last decade. This process forms a worldwide maritime network between the different locations of production and consumption. This network, representing between $80 \%$ and $90 \%$ of world traffic is a major economic concern, including freight distribution, raw materials or energy. Rodrigue demonstrates[1] the economic dependency of energy is increasing in the industrialized countries (North America, Europe, East Asia). The inter-regional trade of oil was 31 million bbl/day in 2002 and is expected to grow up to 57 bbl/day in 2030 [2]. Most of the international traffic use a maritime way, where may occur disruptions. For example, the Suez crisis (1956-1957) caused a closure of the canal, reducing the throughput capacity of transportation. This disruption cost a 2 millions of barrels lost per day. This article focuses on vulnerability of the energy supply, and proposes a methodology to formalize and assess the vulnerability of the network by taking into account the spatial structure of maritime territories.
\end{abstract}

Keywords - maritime network, maritime territories, network modelling, maritime safety and security.

\section{INTRODUCTION}

Today, the supply chain of energy has a global dimension, connecting major consumers (East-Asia, North America) to major producers (Middle-East, Russia). Most of this trade is done on the maritime territories, which represent $40 \%$ of the supply of petroleum and $25 \%$ of gaz (Institut Supérieur d'Economie Maritime). The energy security is a major issue for global economy. The International Energy Agency (IEA) defined energy security as "the uninterrupted availability of energy sources at an affordable price" [2]. To ensure the security of the supply chain, the understanding of possible disruptions is necessary. The aim of IEA is to "maintain and improve systems for coping with oil supply disruptions". The severity of a disruption can be measured by energy lost, level of commercial inventories, the duration of the disruption and the available spare production capacity. Disruptions on the supply chain can be due to environmental causes (extreme weather conditions), maritime activities (collisions, infrastructures failures) or deliberate acts like piracy and terrorist attack. To ensure theses disruptions, two emergency responses are used by IEA, the increase of supply, by stockdraw and production surge, and demand reducing, by restraint and switching energy type. This network can be model by the use of graph.

Indeed, geography and spatial reasoning can highlight new knowledge about supply chain security. The aim of this work is to propose a methodology to formalize and asses the vulnerability of the network by the access of spatial possibilities offered by ocean spatial structure. To achieve it, a state of the art of different modelling of network is detailed in Section II. Then, Section III describes the spatial structure of the ocean and effects of "territorialization" on maritime territories. Section IV focus on vulnerability measurement of the network. Section V presents the methodology and the different steps to assess the vulnerability. Finally, the paper ends with a discussion on the further works.

\section{GRAPH THEORY AND MARITIME NETWORK MODELLING}

Modelling the supply chain by a network offers several advantages. Graphs can describe the topological relation existing between consumers and production through space and quantifies the flow of energy with a ponderation of the graph. This section first describes the properties of graphs then the existing modelling of maritime network and these limitations to access vulnerability.

\section{A. Properties of graphs}

Graph theory is mainly used for network modeling. Most of the studies on maritime networks use graph theory. Indeed, network analysis is used to studyy transport network forms and structures[1]. Networks are modelled by graphs for several reasons: 
- The main strength of graph theory is to allow the description of the topological relationship between several nodes, describing links between locations. This allows studying the connectivity and the degree distribution of every location in a topological space. Those concepts are essential for the study of networks.

- In the case of spatial network the vector and geometric proprieties are very useful. Vectors properties are used to add a direction to a link. For transportation modelling, this property is used to model flows between locations. Geometrics properties can be used to insert distance into the model. This allows spatializing the network in a Euclidian space. It is essential for the modelling of transport.

- Graph theory allows also the description of relationships through the graph. These properties based on the concept of path (a course between components into the graph) and cycle (a path have the same origin and destination) allow the study of relationships between various parts of the graphs.

Theses mathematical properties of graphs are primarily used for the static and dynamic modelling of a transport network.

\section{B. Maritime network modelling}

Few works have been done on modeling of maritime networks. These studies focus on several research questions on maritime network modelling:

- The topological properties of the network and formalization of these transportation networks. Most of them use nodes as ports and links as a maritime flow between ports.

- The configuration of the maritime network and its relationship with the land areas.

- The identification of groups (global regions, clusters...) into the maritime network.

Joly[3] was the first to model the maritime networks using graph theory, with data from the Naval Llyod's insurance company. Each point corresponds to a port, each relation to a link. Veenstra et al.[4] model the maritime networks in three levels: the first level corresponds to infrastructure (ports), the second level corresponds to the ports used by shipping lines and the third one to quantification of the previous levels (e.g. transported volumes, frequencies of transport). The goal of their research is to measure the attractiveness of a port within a network. The purpose of the study of $\mathrm{Hu}$ and $\mathrm{Zhu}$ [5] is to demonstrate that the shape of global maritime network is a "network of small world" which is characterized by the presence of cliques (a sub-graph where all the nodes are connected) and "scale free", following a power law, with high degrees of correlation nodes (hubs) and lower ones (spokes). Ducruet[6] models the network with a multigraph. The result is a hierarchy of ports and shipping lines depending of nodal regions. Zavitsas[7] proposes a model to determine the vulnerability of the maritime supply chain. His methodology consists to create a grid on the maritime space and simulate paths by a shortest path algorithm to obtain a network. Xu et al.[8] propose a network based by grouping seaboards to analyze the evolution of the maritime network between different parts of the world. Kaluza et al.[9] propose a model to compare the different network forms by ships type (container ships, bulk dry carriers, oil tankers...).

All of these modelling are illustrated in (Fig. 1). The figure compares the different structure of maritime network proposed in scientific papers. Circles represent maritime space, nodes the different locations linked (ports for most of them) and links the structuration of network. Links differentiation correspond to the 3 levels of network in Veenstra et al[4] modelling and different type of ships into Kaluza et al[9] modelling.

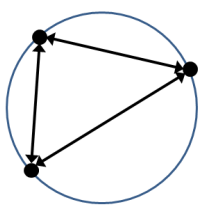

Joly (1995)

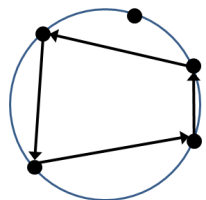

Hu et Zhu (2009)

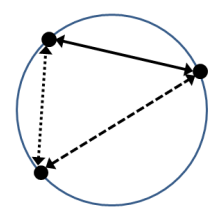

Veenstra et al (2005)

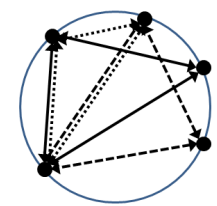

Kaluza et al (2010)

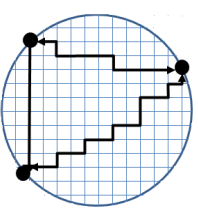

Zavitsas (2011)

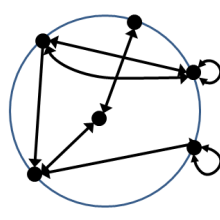

Ducruet (2013)

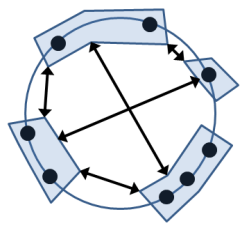

Xu et al (2014)
Figure 1. Maritime network modelling using graph theory

\section{Limitation of these works in our case study}

However, these works are limited to provide useful information for safety and security on the sea. These models provide any information on the maritime territory crossed by ships. Indeed, the proposed models use ports as nodes and links as roads. The only exceptions are some checkpoints such as channels (Suez, Panama) used in the model of Ducruet [6]

In his modelling, Zavitsas[7] uses the shortest route between the port of departure (supply) and arrival (demand) through a cost-distance matrix and justifies this choice by the lack of 
available information on maritime territory. Veenstra et al [4] don't model the sea routes because they do not consider the maritime space as a physical space "There are no physical links between airports and between seaports that have the characteristic of a line". The work of $\mathrm{Hu} \& \mathrm{Zhu}[5]$ only focuses on the shape of the maritime network and do abstraction of space.

A spatial reasoning about the space crossed by ships is missing or not covered in the existing works on maritime flows modelling. Due to the specific research question behind these modelling, mainly focuses on relationship between ports, maritime territories are not present into the conceptual framework. Indeed, there are no modelling approach who tries to understand the relationship between transportation and the spatial structure of the ocean. But ocean isn't an empty and homogeneous place. Moreover, to measure the vulnerability by topological and geometric features, a specific model of maritime space is needed. Indeed, measure the influence of ports between them and their topological properties is not sufficient under this research.

To obtain this model, it will be necessary to integrate the structuring elements of maritime territory in the previous section to formalize a network capable of representing the topology of the maritime area. The problematic of this study is to find a new methodology to build this network, and understand relationships between the economical use of ocean (the maritime network) and the structuration of maritime space (maritime territories). Our hypothesis is that dynamic structure of maritime space under the effect of risky situations may induce disruptions on the network, and affects the performance of the supply chain of energy.

\section{TERRITORIALIZATION AND SPATIAL STRUCTURATION OF MARITIME SPACE}

Our goal in this work is to formalize a network based on the spatial structure of ocean. To achieve it, we have to understand how the maritime territories are forms. Indeed, through these maritime territories, the maritime network is forms by the used of space into the maritime territories. With this methodology, we can understand the structuration of the maritime network.

\section{A. Typology of network by structuration}

Three types of network are distinguish depending to their spatial structuration[1]: strictly defined and delimited, vaguely defined and delimited, or immaterial. In a strictly defined and delimited network, the space occupied by the transportation network is strictly reserved for the use of transport and can be identified on a map. An appropriation of this space for transportation purposes can be established, the network structure is dependent on infrastructure. This is the case of road and rail networks. In the vaguely defined and delineated networks, as maritime and aerial networks, the space can be shared by multiple activities, there is no appropriation of space, only rights of way. Infrastructures are exclusively areas of departure and arrival. Finally, some networks, such as wireless communication networks are immaterial and have no spatiality

In the case of maritime transportation, the possibility of the maritime space isn't constraint by an infrastructure and can use all the opportunities available at sea.

\section{B. Spatial propriety of maritime space}

Between ports, the network crosses maritime space, which corresponds to the entire ocean. This space may be considered by its topological properties, connexity and connectivity:

- Connexity means that the maritime space does not have any discontinuity within its space and maritime space therefore is totally connected. This means that from a port, it is theoretically possible to reach all the other ports.

- Connectivity is measured by the degree of freedom (k) is theoretically infinite as the ocean is not limited by a network-support (as is the case for road or rail) and therefore, there is an infinite number of ways to connect the ports (Fig. 2)

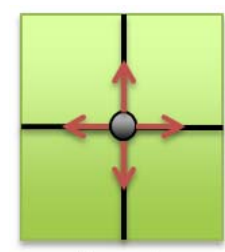

$\mathrm{k}=4$

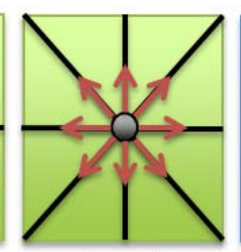

$\mathrm{k}=8$

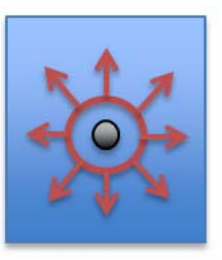

$\mathrm{k}=\infty$
Figure 2. Connectivity of maritime space

However, this degree of freedom is only theoretical, because in practice other structural logics (e.g economical, legal) are sea routes and spatial constraints for the transportation within the maritime space.

\section{Territorialization and spatial constaints}

This process of maritimization has an impact on maritime spaces. This increasing use of space as for transport and exploitation has resulted in a territorialization of maritime spaces. Di Meo[10] defines the concept of territory, distinguishing its two components: an infrastructure and a superstructure. Infrastructure refers to concrete aspects of territories: it consists of a geographical instance through the construction of concrete space (ports, off-shore structures ...) and economic proceeding involves a spatial organization of transportation and exploitation in the territory. These instances are managed by the superstructure, consisting in a representation of the territory and a political and legal case involving power over the space considered, at the same time 
international (Montego Bay convention) and national (e.g. EEZ, territorial seas).

This territorialization process forms geographical, legal and economic constraints, related to maritime territories. Constraints are formalized as barriers on the maritime network and explain the overall structure of the maritime network. Rodrigue[1] distinguishes two types of barriers for transport networks: the absolute and relative barriers.

The absolutes barriers prevent all movements within the network. In a maritime network, this is the land/sea interface which corresponds to the limit of the maritime space. Indeed, the land/sea interface is a discontinuity and therefore is characterized by an impassable limit.

Relative barriers reduce and restrict the degree of freedom and the space connectivity. Thus, they affect the routes used to connect two parts of the network. They correspond to the capes, straits, channels, iceberg, restricted area, weather, and any element affecting the freedom of use in maritime space.

These structural elements (physical constraints and political boundaries) explain the configuration of maritime lines between the ports. Indeed, they have an influence by degree of constraint on the maritime network structure.

\section{NETWORK VULNERABILITY MEASUREMENT}

The structure of the maritime network has an impact on the maritime network vulnerability. The main problematic of transport network is the accessibility of locations. This accessibility is measured by the degree of connectivity into the network. To assess the vulnerability of a network, several indicators are used.

\section{A. Typology of vulnerability measurements}

Connective and access vulnerability, robustness and reliability are the three mains indicators to measure the impact of disruptions. These three concepts are complementary and rely on different conceptualizations of network security:

\section{1) Connective and access vulnerability}

Zavitsas[7] defined network vulnerability both as a probability of occurrence of a disruption on a network and as a degree of degradation resulting in a performance drop once the disruption performed.

The two fundamentals notions to measure the vulnerability are accessibility and connectivity. D'Este and Taylor[11] differentiate the "connective vulnerability" and "access vulnerability". The connective vulnerability involves the configuration of the links. It is related to the extension of the shortest paths, a link between two nodes is vulnerable when the degradation following a disruption increases the cost of travel between two nodes. The access vulnerability focus on nodes in the graph: a node is vulnerable if a disruption greatly reduces its accessibility.

\section{2) Robustness}

Robustness refers to the network's ability to normally function despite a malfunction of a component following a disruption [12]. Static robustness refers to the ability to maintain connectivity after random removal of part of the network. Dynamic robustness is interested in redistribution of flows after a disruption.

\section{3) Reliability}

Reliability is a user-oriented view of vulnerability. The most common definition is from Wakabayshi and Iida [13] which is the probability that the system works properly for a period when the user tries to use the system.

\section{B. A structural vulnerability of transport networks}

The work of Gleyze[14] distinguishes the different aspects of the vulnerability of a network. This work is interesting for our research because the conceptual framework used in this work isolates structural measurement for the network.

Gleyze[14] identifies three parts in the vulnerability of networks: the material part, the structural part and the functional part. The material part refers to the potential of the network infrastructure damage (e.g. roads, railways, stations, ports), the structural aspect determines the network relational (ability to connect each part of the network) and the functional aspect indicates the vulnerability for the transportation services offered by the network. These three vulnerabilities are linked, for example, if a road is vulnerable to a flood (material vulnerability), it will directly affect the potential of the relational network (structural vulnerability) and therefore the use of the network (functional vulnerability).

This distinction isolates the spatial structure through the conceptualization of the notion of structural vulnerability. The network is described as a mediator, a relational object linking different parts of the ocean (in this case of study). Through this conceptual framework, we can use spatial properties on the network (topology, geometric) to measure the network vulnerability.

\section{Measurement of network efficacity and solicitation}

Gleyze uses two main measures to determine the structural vulnerability: network efficiency, which is the degree of degradation of the disruption, and the network solicitation, which is the structural response of the network use after a disruption.

The network efficiency measures vulnerability facing network disruption by the degradation of effectiveness at local and global levels. The average distance is used to measure for each given component its accessibility. In case of disruption, 
overall efficiency is calculated by the additional length (distance, time or cost) to connect all points of the network.

The second measure used is the network solicitation. It allows the understanding of the impact of a disruption in terms of redistribution of relationships on the network. It measures the total weight of the shortest paths on each component. After a disruption, it can distinguish which component will be solicited and therefore how the network uses the structure to respond to the disruption.

This conceptual framework and associated measurements are useful in our work. Nevertheless, to use the concept and measurement of structural vulnerability, we have to adapt them to our specific study case. Gleyze work focuses on urban networks but maritime transportation has is own specificity: the transportation possibilities are not a set of way but a surface with infinite deviational possibilities. To obtain an assessment of maritime network, we have to propose a model taking into account theses specificities.

\section{MODELLING THE MARITIME NETWORK VULNERABILITY}

The territorialization of maritime space results in a spatial differentiation. This process creates heterogeneity into this space, and maritime territories have different features depending of their location and spatial content. For transportation, this can have effect on the safety and security at sea. Some areas within the maritime space facilitate or hinder transportation. According to the spatial features of territories, maritime space can ease or reduce transportation possibilities. For example, a high traffic density area or a stormy weather area in the ocean can reduce the accessibility and affects the efficacy of transport.

\section{A. Measuring vulnerability at sea}

We aim to measure efficacy to improve knowledge on the relationship between the ocean as spatial structure and the network as spatial use of this structure. As seen before we will use the framework of structural vulnerability defined by Gleyze and these measurements: efficacy and solicitation. Vulnerability can be access by the difference of efficacy and solicitation between a regular configuration of the network and a network configuration after disruption.

A disruption causes a deviation of regular use of the spatial structure (e.g weather condition). To avoid these impacted spaces, ships have to crossed additional distance. According to Gleyze[14] efficacy is the total length to reach all nodes into the graph. In our study case, we focus on the total length to reach ports.

Solicitation is measured by the number of shortest paths transiting thought a corposant of the network. Basically, this corresponds to the maritime territories crossed by ships. After a disruption, territories used for the deviation became shortest paths for several destinations, causing a change into the maritime territories. This means they are variations into each maritime territory.

In maritime transport, additional distance becomes a lengthening of the total time of travel. This additional time is an extension of the cost of each travel. Time lost has a global impact on the economy, by a decrease of transport efficacy. To model it, we have to add locations reached during a disruption.

\section{B. Creating location into the maritime network}

The first step in the process is to create locations within the maritime space. These locations are elements that guide and influence ships direction and speed during travel. These locations do not necessarily have the same ability to influence the trip. These are capes, channels, straits, TSS as checkpoints for the trip, or barriers for navigation like stormy area or piracy zone. Each location within the space can produce knowledge on the territory and spatial differentiation.

These constraints are the structural elements of the maritime territory. The primary advantage of this approach is to create geographic data for a better understanding of maritime territories. In this figure(fig), 3 ports are link by the maritime space and 3 constraints exist into the space. $\mathrm{C} 1$ and $\mathrm{C} 2$ are checkpoints (TSS, good weather) and C3 a zone to avoid (piracy zone).

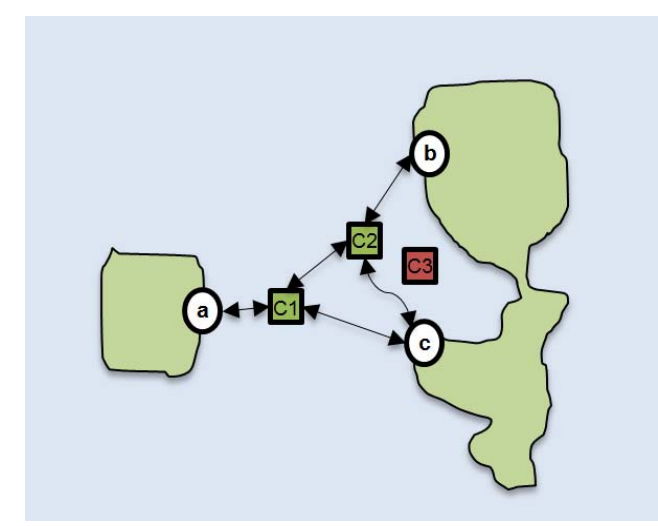

Figure 3. Ports and constraints into the maritime space

This methodology is used to provide information on the maritime territories to formalize the network.

\section{Network formalization}

The second step in the process is to link these constraints (checkpoints or barriers). A sea route can be defined as a directed path between ports of origin and destination with a succession of passages and intermediate ports, Paths can be defined like a sequence of location to reach or to avoid (in case if the barriers is on the shortest path between two nodes): 


$$
\begin{gathered}
\mathrm{AB}=(\mathrm{A}, \mathrm{c} 1, \mathrm{c} 2, \mathrm{~B}) \\
\mathrm{AC}=(\mathrm{A}, \mathrm{c} 1, \mathrm{C}) \\
\mathrm{BC}=(\mathrm{B}, \mathrm{c} 2,-\mathrm{c} 3, \mathrm{C})
\end{gathered}
$$

For example, a trip form port $\mathrm{B}$ to port $\mathrm{C}$ will start to $\mathrm{B}$, go thought node $\mathrm{c} 2$, avoid node $\mathrm{c} 3$ and reach port $\mathrm{C}$. This step formalizes topological structure to the maritime network by maritime territory constraints. This formalization allows the topological representation of the use of space for transport (fig. 4). ). This results in a graph, and represents the maritime space and the constraints of territory. Ports, as entry and exit door of maritime areas are located outside, and maritime constraint are inside the maritime space.

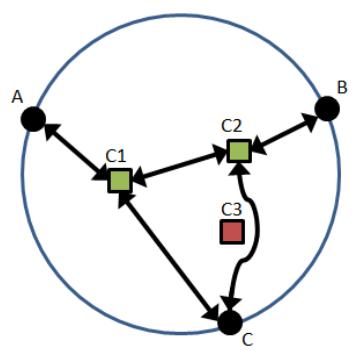

Figure 4. Proposed topological structure of maritime network

\section{Measering maritime network vulnerability}

From this formalization, the maritime network structure is able to measure the vulnerability of the network into the maritime space. A disruption corresponds to a change of state of attractive constraints into repulsive constraints. Zavitsas [7] demonstrate that the strongest disturbances are related to the closure of ports and channels (attractive to a repulsive place for navigation). By using structural vulnerability measurement established by Gleyze[14] we can assess the maritime network.

\section{FURTHER WORKS AND CONCLUSION}

Further works will focus on the modelling of the territory by a spatial agent based model, as propose by Langlois[15] to highlight effects of constraints in the maritime space. This methodology will allow to define territorial behaviors (attractive or repulsive for navigation) and to measure the influence and territorial dynamics on the navigation.

Indeed, these attractive or repulsive constraints can affect a entire territory for navigation and change the constraint degree and attraction of a place into the ocean it is possible to know the influence of a place on the maritime space. Depending on the behavior of the place (checkpoint or absolute barrier), the territory can be split into several locator agent. These spatial agent can be attractive, repulsive or neutral (no significant effect on navigation) depending of the constraints into the territories.
Ultimately, the goal of this study is to demonstrate the spatial structure effects on spatial behaviors and conversely, spatial behaviors change the configuration of the spatial structure. To achieve it, multi-agent model will be used to simulate the dynamic of territories (attractive and repulsive zones) and its possible effects on spatiotemporal behaviors of ships. This can contribute to a better comprehension of the worldwide maritime network, its formalization and evolution, its performance as a spatial mediator, and its impact on the global economy.

\section{REFERENCES}

[1] J.-P. Rodrigue, C. Comtois, et B. Slack, The geography of transport systems. 2013.

[2] IEA, « Energy eupply security report. » 2014.

[3] O. Joly, « Structuration des lignes maritimes régulières de navires porte-conteneurs », Théo Quant, 1995.

[4] A. W. Veenstra, H. M. Mulder, et R. A. Sels, " Analysing container flows in the Caribbean », $J$. Transp. Geogr., vol. 13, n 4, p. 295-305, déc. 2005.

[5] Y. Hu et D. Zhu, « Empirical analysis of the worldwide maritime transportation network », Phys. Stat. Mech. Its Appl., vol. 388, n 10, p. 2061-2071, mai 2009.

[6] C. Ducruet, « Network diversity and maritime flows », J. Transp. Geogr., vol. 30, p. 77-88, juin 2013.

[7] K. Zavitsas, « The Vulnerability of The Petroleum Supply Chain », Imperial College London, 2011.

[8] M. Xu, Z. Li, Y. Shi, X. Zhang, et S. Jiang, « Evolution of regional inequality in the global shipping network », J. Transp. Geogr., vol. 44, p. 1-12, avr. 2015.

[9] P. Kaluza, A. Kolzsch, M. T. Gastner, et B. Blasius, « The complex network of global cargo ship movements », J. R. Soc. Interface, vol. 7, n ${ }^{\circ} 48$, p. 1093 - 1103, juill. 2010.

[10] G. Di Méo, « La géographie culturelle : quelle approche sociale ?», Ann. Géographie, vol. 660-661, $\mathrm{n}^{\mathrm{o}} 2$, p. 47, 2008 .

[11] G. . D’Este et M. A. . Taylor, « Modeling network vulnerability at the level of the national strategic transport network », J. East Asian Soc. Transp. Stud., vol. 4, 2001.

[12] M. Snelder, « The importance of alternative routes for the robustness of a road network », Int. Conf. Infrastruct. Syst., 2008.

[13] H. Wakabayashi et Y. Iida, « Upper and lower bounds of terminal reliability of road networks: an efficient method with boolean algebra ", J. Nat. Disaster Sci., 1992.

[14] J.-F. Gleyze, « La vulnérabilité structurelle des réseaux de transport dans un contexte de risques. »

[15] P. Langlois, Simulation des systèmes complexes en géographie. Paris: Hermes. Lavoisier, 2010. 